\title{
Comparison of Multiwalled Carbon Nanotubes and a Conventional Absorbent on the Enrichment of Sulfonylurea Herbicides in Water Samples
}

\author{
Qingxiang ZHOU, ${ }^{* \dagger}$ Junping XIAO, ${ }^{* *}$ and Weidong WANG* \\ *School of Chemistry and Environmental Sciences, Henan Normal University, Henan Key Laboratory \\ for Environmental Pollution Control, Xinxiang 453007, P. R. China \\ **Department of Chemistry, University of Science and Technology Beijing, Beijing 100083, P. R. China
}

\begin{abstract}
Recently, multiwalled carbon nanotubes (MWCNTs) have been at the center of attention because of their applications in many fields. Efforts to investigate the possibility of MWCNTs as SPE absorbents for the enrichment of environmental pollutants yielded positive results. The goal of the present work was to compare the enrichment power of MWCNTs with that of regular adsorbents, such as C18 silica for SPE of five sulfonylurea herbicides. The results indicated that multiwalled carbon nanotubes were very suitable for the preconcentration of sulfonylurea herbicides in complex water samples, yielding better recoveries. C18 gave a lightly lower enrichment performance, and could not enrich nicosulfuron in complex samples. All of these experimental results indicated that multiwalled carbon nanotubes could be used as a valuable alternative adsorbent for the SPE of sulfonylurea herbicides in many real water samples.
\end{abstract}

(Received January 26, 2006; Accepted June 5, 2006; Published February 10, 2007)

Sulfonylurea herbicides are important agricultural chemicals with very high herbicidal activity and low dose rates for the control of many grasses and broadleaf weeds. These compounds can enter the environment through all kinds of ways. However, their presence in the environment could influence the growth of susceptible plants due to the environmental conditions, such as high $\mathrm{pH}$, low temperature, little rainfall and poor microbial activity. ${ }^{1}$ These compounds might lead to severe environmental pollution from the accumulation of such compounds, which enter the environment by many ways. Rapid, sensitive and selective determination methods are crucial to evaluate these compounds concerning their environmental safety. Yet, it is a great challenge because of the very low concentration present in the environment of these compounds, as well as their polarity and thermal instability. Many methods have been developed for the analysis of these herbicides based on liquid chromatography with UV detection, ${ }^{2,3}$ capillary electrophoresis, ${ }^{4}$ LC with mass spectrometry, ${ }^{5,6}$ immunoassay, ${ }^{7}$ bio-assay. ${ }^{8}$ Ayano et al. established a new method for the selective separation and determination of sulfonylurea herbicides using a novel LC column packed with poly( $N$-isopropylacrylamide) by controlling the external column temperature, while making use of a reversible change in the hydrophilic/hydrophobic properties of polymer poly $(N$-isopropylacrylamide) in response to a change in the temperature. ${ }^{9-11}$ This method, based on temperature responsive chromatography, is environmental friendly and is of value in the analysis of environmental pollutants, due to the fact that it consumes no organic solvents and only has an aqueous mobile phase.

Advanced techniques, such as LC-MS or high resolution MS, can give better detection sensitivity. However, the cost of these

$\doteqdot$ To whom correspondence should be addressed.

E-mail: zhouqx@henannu.edu.cn techniques is too high for most laboratories. Among alternative techniques, solid-phase extraction has been used in environmental sample analysis for trace analytes. Solid phase micro-extraction (SPME), a solvent-free extraction technique established in $1990,{ }^{12}$ is also a procedure for sample treatment, offering the cleanup and preconcentration of analytes in only one step. The combination of SPME and gas chromatography-mass spectrometry can provide efficient enrichment and cleanup, and also good selectivity and sensitivity, and has been applied into the analysis of many kinds of pollutants in various fields.

In order to achieve valuable and effective absorbents for the SPE of the target analytes, new kinds of absorbents for improving the enrichment performance are needed. For example, molecularly imprinted polymers have been synthesized and used as recognition matrixes in a coupled SPE system in order to enhance the specificity and selectivity for sulfonylurea herbicides. ${ }^{13}$ In recent years, a novel carbonaceous material, multiwalled carbon nanotubes (MWCNTs), was successfully observed to absorb increasing attentions. On the basis of their peculiar electronic, metallic and structural characteristics, ${ }^{14}$ they have been exploited in analytical and other fields, such as biosensor, ${ }^{15}$ modified electrode, ${ }^{16}$ and fieldeffect transistors. ${ }^{17}$ The results of preliminary studies demonstrated that CNTs had high enrichment efficiency for the adsorption of dioxins. ${ }^{18}$ Cai et al. also used MWCNTs as adsorbents for the preconcentration of phthalate esters, bisphenol A, 4-n-nonylphenol and 4-tert-octylphenol and chlorophenols from environmental water samples for chromatographic analysis. ${ }^{19-21}$ Liang et al. applied MWCNTs packed in a cartridge, pretreated with nitric acid, to concentrate heavy metal ions of $\mathrm{Cd}, \mathrm{Mn}$ and $\mathrm{Ni}^{22}$ Our group ${ }^{23,24}$ reported excellent enrichment performance of MWCNTs for atrazine and simazine. However, sulfonylurea herbicides have much lower hydrophobic properties than atrazine and simazine because their 
octanol/water partition coefficients $\left(K_{\text {ow }}\right)$ were several magnitudes lower than that of atrazine and simazine. Meanwhile, from a chemical view, there are several hydrophilic groups in the molecules of sulfonylurea herbicides. That is to say, it is difficult to preconcentrate of them. It is obvious that it is of great importance to extend the application of MWCNTs in environmental fields if MWCNTs have better enrichment capacities for sulfonylurea herbicides. The goal of this study was to investigate the trapping capability of MWCNTs and to compare the enrichment efficiency of MWCNTs with C18 using sulfonylurea herbicides as the model compounds.

\section{Experimental}

\section{Reagents and chemicals}

Nicosulfuron (NS), triasulfuron (TS), metsulfuron-methyl (MSM), thifensulfuron-methyl (TSM) and bensulfuron-methyl (BSM) standards at a concentration of $100 \mu \mathrm{g} \mathrm{ml}^{-1}$ were purchased from Institute of Environmental Protection and Monitoring, Department of Agriculture (Beijing, China). Working solutions were prepared daily by appropriate dilution of the stock solutions with water. LC-grade acetonitrile and methanol were obtained from Scharlau Chemie SA (Barcelona, Spain). Ultrapure water was prepared in the lab using a water-treatment device, "Ultra-Clear" (SG Wasseraufbereitungsanlagen, Barsbüttel, Germany). All other solvents and reagents used were of analytical reagent grade, unless stated.

Multiwalled carbon nanotubes with an average external diameter of $30-60 \mathrm{~nm}$ were kindly provided by Tsing-Nafine Nano-Powder Commercializition Engineering Center, Chemical Engineering Department of Tsinghua University (Beijing, China). Before use, MWCNTs were dried at $80^{\circ} \mathrm{C}$ for $2 \mathrm{~h}$. Agilent ZORBAX SPE C18 (EC) cartridges were purchased from Agilent Corp., USA. All of the glassware used in the experiments were cleaned with pure water, and then soaked in 6 mol $\mathrm{l}^{-1}$ nitric acid for $24 \mathrm{~h}$, before washing with purified water.

\section{Apparatus}

The MWCNTs and C18 packed cartridge used in these experiments were prepared by modifying an Agilent ZORBAX SPE C18 (EC) cartridge ( $0.2 \mathrm{~g}, 3 \mathrm{ml}$, polypropylene). The C18 packing was evacuated, and $0.1 \mathrm{~g}$ multiwalled carbon nanotubes and $\mathrm{C} 18$ were packed in the cartridges, respectively. The polypropylene upper frit and lower frit were retained at each end of the cartridge to hold the carbon nanotubes packing in place. Then, the outlet tip of the cartridge was connected to a Model SHZ-3(III) vacuum pump (Yuhua Instrument Co., Ltd., Zhengzhou, Henan), and the inlet end of the cartridge was connected to a PTFE suction tube, whose other end was inserted into the sample solution. In order to reduce the interferences of organic and inorganic contaminants, the entire SPE assembly needed to be washed with sufficient acetonitrile and water.

An Agilent 1100 HPLC system, including an autosampler, a thermostatic cartridge, a vacuum degasser, a quaternary pump and a diode array detector, was employed for the quantitative analysis of the analytes. An Agilent ZORBAX SB-C18 chromatographic column $(2.1 \times 150 \mathrm{~mm}, 5 \mu \mathrm{m})$ was used for separation. The mobile phase was (A) acetonitrile and (B) water containing $0.1 \%$ acetic acid and $1 \%$ methanol at the flow

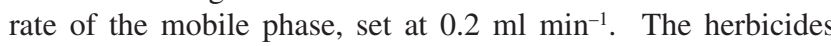
were separated with the following gradient program: maintaining 30\% A for $15 \mathrm{~min}$; followed by a linear gradient from $30 \%$ A for $15 \mathrm{~min}$ to $40 \%$ A for $16 \mathrm{~min}$; then maintaining $40 \%$ A for $24 \mathrm{~min}$ and returning linearly to $30 \% \mathrm{~A}$ in $1 \mathrm{~min}$.
These HPLC conditions were obtained by minimal changes from the reported conditions. ${ }^{13}$ The column temperature was $25^{\circ} \mathrm{C}$, the chromatographic data were acquired at a wavelength of $236 \mathrm{~nm}$ and the injection volume was $50 \mu \mathrm{l}$. Agilent LC-3D ChemStation for LC systems were used to control the chromatographic units, and to acquire and process the chromatographic data.

\section{SPE procedure}

Before use, the SPE cartridges made in our lab packed MWCNTs or C18, were washed with $5 \mathrm{ml}$ acetonitrile and $5 \mathrm{ml}$ ultrapure water. Then, an appropriate volume of sample solutions spiked with these five sulfonylurea hebicides was passed through the cartridge at the maximum flow rate using a vacuum pump. The cartridge was then washed with $10 \mathrm{ml}$ of ultrapure water to remove any coabsorbed matrix materials from the cartridge, and dried under a negative pressure for $30 \mathrm{~min}$. Subsequently, sulfonylurea herbicides retained on the cartridge were eluted with an optimal volume of acetonitrile containing acetic acid. The eluent was blown to near dryness with a mild nitrogen stream at $30^{\circ} \mathrm{C}$; the residue was then dissolved with the mobile phase $(\mathrm{A} / \mathrm{B}=30 / 70)$ up to $0.4 \mathrm{ml} ; 50 \mu \mathrm{l}$ was injected into the HPLC-DAD system for the determination.

\section{Water samples}

In order to validate the applicability of MWCNTs for SPE and to measure the difference in the enrichment capacity between MWCNTs and C18, four environmental water samples from different locations and different water qualities were selected for evaluation, including tap water, reservoir water, seawater and wellwater. A reservoir water sample was gathered from the Zhangwu reservoir in the region of Anyang, Henan province. A seawater sample was obtained from Penglai in the region of Shandong province. Tap water sample was taken from our Laboratory after flowing for $10 \mathrm{~min}$. Well-water sample was obtained from Nanyang, Henan province; its $\mathrm{pH}$ was 6.9 and its main ions were $\mathrm{Na}^{+}, \mathrm{Ca}^{2+}, \mathrm{K}^{+}$and $\mathrm{Cl}^{-}$with concentration of $152.5,5.4,0.8$ and $324.5 \mathrm{mg} \mathrm{l}^{-1}$, respectively. Before use, all the environmental water samples were filtered through $0.45 \mu \mathrm{m}$ micropore membranes and stored in brown glass bottoms at $4^{\circ} \mathrm{C}$.

\section{Results and Discussion}

\section{Optimization of HPLC condition}

The chromatographic parameters are very crucial to gain satisfactory analysis results and will play an important role in developing a new method. Due to the intrinsic physicalchemical properties, a reasonable mobile phase composition is needed for obtaining good separation. Based on the references and the weak acidic nature the sulfonylurea herbicides, an investigation was carried out and the mobile phase was selected including two parts: (A) acetonitrile and (B) water containing $0.1 \%$ acetic acid and $1 \%$ methanol. Good separations of the five sulfonylurea herbicides were achieved under a gradient program with the flow rate of the mobile phase set at $0.2 \mathrm{ml}$ $\mathrm{min}^{-1}$. The gradient program was carried out as follows: maintaining $30 \%$ A for $15 \mathrm{~min}$; followed by a linear gradient from $30 \%$ A for $15 \mathrm{~min}$ to $40 \%$ A for 16 min; maintaining $40 \%$ A for $24 \mathrm{~min}$ and returning linearly to $30 \% \mathrm{~A}$ in $1 \mathrm{~min}$. Therefore, these optimal conditions were set as the analytical chromatographic parameters.

\section{Selection of enrichment parameters}

Possible factors that may influence the enrichment include the 

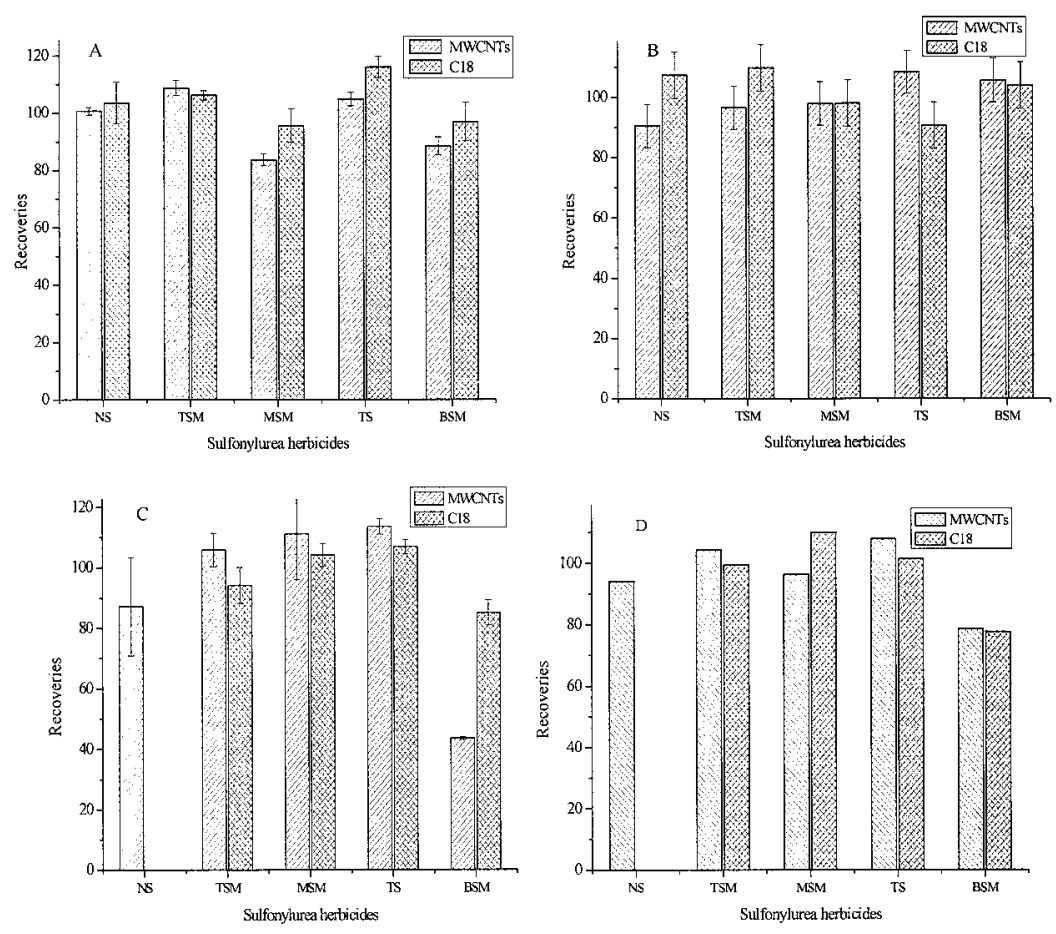

Fig. 1 Extraction performance of five sulfonylurea herbicides from spiked water samples with concentrations of $0.4 \mathrm{ng} \mathrm{ml}^{-1}$ nicosulfuron, thifensulfuron-methyl and bensulfuron-methyl, $0.2 \mathrm{ng}$ $\mathrm{ml}^{-1}$ for metsulfuron-methyl and $0.8 \mathrm{ng} \mathrm{ml}^{-1}$ for triasulfuron using carbon nanotubes and $\mathrm{C}_{18}$, respectively. A, Tap water samples; B, reservoir water samples; C, seawater samples; D, well-water samples. NS, Nicosulfuron; TSM, thifensulfuron-methyl; TS, triasulfuron; MSM, metsulfuronmethyl; BSM, bensulfuron-methyl.

eluent and its volume, sample volume, $\mathrm{pH}$ of the sample and flow rate of the sample. These parameters will place an important role on the concentration of the target analytes. Based on the experimental results, the optimal parameters were determined as follows: $12 \mathrm{ml}$ of acetonitrile containing $1 \%$ acetic acid was used as the eluent. The flow rate of the water sample solution always contributes a significant impact to the concentration factor in the procedure. However, the preexperiments indicated that the flow rate has no effect on the enrichment efficiency of sulfonylurea herbicides. The maximum flow rate was employed to shorten the experimental time. The $\mathrm{pH}$ of the sample solutions was adjusted to 3 for the extraction of sulfonylurea. The sample volume was $500 \mathrm{ml}$ for SPE extraction.

C18 silica is a popular absorbent for SPE in the environmental analytical field because it has a much better preconcentration performance for many organic pollutants in the environment. Our preliminary experiments and many published research work involved in using this adsorbent as a packing for SPE are in agreement with it. For easily comparing, the content and the parameters are all the same as that of MWCNTs SPE.

\section{Comparison of the enrichment performance}

The baseline separation of five sulfonylurea herbicides was achieved under the optimal conditions mentioned above, and a comparison was made of the enrichment performance involved in four real water samples, such as tap water, reservoir water, seawater and well-water. Samples were pretreated before use and spiked with the same analyte concentration, before duplicate blank experiments were performed on spiked samples. Triplicate extractions were performed for each spiked water sample and each adsorbent. The results are shown in Figs. 1A -
D. The experiments showed that no target analytes were in the blank samples. From Figs. 1A - D, we can see that these two absorbents exhibit different extraction capabilities. When the matrices of the samples were very simple, such as tap water and reservoir water, the enrichment performance between the two adsorbents had no significant difference. The enrichment capacity of $\mathrm{C} 18$ was slightly higher than that of MWCNTs because the spiked recoveries of MSM, TS and BSM were slightly larger than that obtained with MWCNTs for the tapwater samples. The preconcentration of NS and TSM using C18 was better than that using MWCNTs when reservoir water was investigated, yet the enrichment performance of TS with MWCNTs was excellent relative to $\mathrm{C} 18$. However, with complex matrices, the situation changed. Here, MWCNTs demonstrated better enrichment performance for the five sulfonylurea herbicides in seawater and well-water samples. The recovery of BSM was very low from the seawater sample, which may have been due to the presence of other substances in seawater, leading to a rapid degradation of the bensulfuronmethyl analyte under acidic conditions. In the latter two complex water samples, only MSM in the well-water sample, and BSM in the seawater sample, exhibited a slightly higher extraction performance, and the enrichment factors of the other sulfonylurea herbicides were all lower than that from MWCNTs. Moreover, TS could not be trapped with C18 from the latter water samples, and much better recovery was achieved using MWCNTs. Usually, the sample matrices play an important role in the enrichment of analytes aside from the $\mathrm{pH}$ and flow-rate effects. From the above discussion, we can see that MWCNTs are better absorbents than commonly available packing materials for SPE in environmental analysis. Figure 2 demonstrates that MWCNTs was superior to $\mathrm{C} 18$ for the 


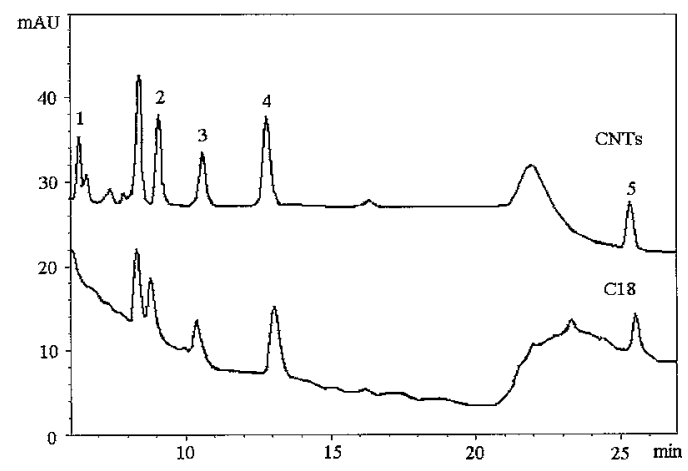

Fig. 2 The chromatogram of five sulfonylurea herbicides in spiked well water enriched by carbon nanotubes and $\mathrm{C} 18$, and the spiked concentration was as the same of Fig. 1. Peak identification: 1, nicosulfuron; 2, thifensulfuron-methyl; 3, triasulfuron; 4, metsulfuron-methyl; 5, bensulfuron-methyl.

enrichment of target herbicides in well-water samples, and the matrices effect was much lower for MWCNTs. In order to make MWCNTs easier to be used in environmental applications, the linear range, detection limit, productivity and precision were all investigated in detail using ultrapure water. The related values are listed in Table 1. The detection limits of these five analytes were obtained based on the signal as threefold the baseline noise $(S / N=3)$ for the extraction of a $500 \mathrm{ml}$ water sample. The precisions (RSD) were obtained from six determinations of spiked samples. A method based on enrichment with MWCNTs as SPE packing has achieved good spiked recoveries from four different environmental water samples, which has proved that this method could be well applied to the analysis of real-world water samples.

\section{Conclusions}

A comparison of the enrichment power between MWCNTs and C18 for SPE of sulfonylurea herbicides in environmental water samples was made. The results indicated that multiwalled carbon nanotubes had much better extraction capacity for the target, five-sulfonylurea herbicides in complex water samples, and had a similar extraction performance to that of $\mathrm{C} 18$ silica in water samples with simple matrices. In contrast, MWCNTs will be more suitable to extract sulfonylurea herbicides in complex samples. In a word, MWCNTs would be a valuable and alternative absorbent for the trace-level analysis of sulflonylurea herbicides, and will be widely used in analytical and environmental fields.

\section{Acknowledgements}

This work was supported by Natural Science Foundation of Henan Province (No. 0511053000), the Youth Science Foundation of Henan Normal University (2004005), and Creative Talented Person's Fund of Henan province (High Teaching [2005]-126) and grants from the Henan Key Laboratory for environmental pollution control.

\section{References}

1. G. M. Fahl, L. Kreft, R. Altenburger, M. Faust, W. Boedeker, and L. H. Grimme, Aquat. Toxicol., 1995, 31, 175.

2. E. W. Zahnow, J. Agric. Food Chem., 1985, 33, 479.
Table 1 Related parameters for the proposed method with MWCNTs as adsorbents for SPE

\begin{tabular}{|c|c|c|c|c|c|c|}
\hline \multirow[t]{2}{*}{ Compound } & \multirow{2}{*}{$\begin{array}{l}\text { Linear } \\
\text { range/ } \\
\text { ng ml }{ }^{-1}\end{array}$} & \multicolumn{2}{|c|}{$\begin{array}{l}\text { Linear } \\
\text { regression } \\
\text { parameter }\end{array}$} & \multirow[t]{2}{*}{$R^{2}, \%$} & \multirow{2}{*}{$\begin{array}{c}\text { Detection } \\
\text { limit/ } \\
\mathrm{ng} \mathrm{l}^{-1}\end{array}$} & \multirow[t]{2}{*}{$\begin{array}{c}\mathrm{RSD}, \% \\
(n=6)\end{array}$} \\
\hline & & $a$ & $b$ & & & \\
\hline NS & $0.04-40$ & -149.7 & 287.9 & 99.90 & 6.8 & 2.5 \\
\hline TSM & $0.04-40$ & -125.8 & 385.1 & 99.96 & 11.2 & 5.4 \\
\hline MSM & $0.02-20$ & -158.4 & 647.9 & 99.88 & 5.9 & 2.1 \\
\hline TS & $0.08-80$ & -207 & 265.5 & 99.93 & 22.4 & 2.6 \\
\hline BSM & $0.04-40$ & -154.4 & 135.9 & 99.38 & 2.9 & 4.8 \\
\hline
\end{tabular}

a. $Y=a+b X$.

NS, Nicosulfuron; TSM, thifensulfuron-methyl; TS, triasulfuron; MSM, metsulfuron-methyl; BSM, bensulfuron-methyl.

3. A. C. Hogenboom, U. K. Malmqvist, K. Nolkrantz, J. J. Vreuls, and U. A. Th. Brinkman, J. Chromatogr., A, 1997, 759, 55.

4. G. Dinelli, A. Vicari, A. Bonetti, and P. Catizone, J. Agric. Food Chem., 1997, 45, 1940.

5. N. Wang and W. L. Budde, Anal. Chem., 2001, 73, 997.

6. E. Ayano, H. Kanazawa, M. Ando, and T. Nishimura, Anal. Chim. Acta, 2004, 507, 215.

7. J. F. Brady, J. Turner, and D. H. Skinner, J. Agric. Food Chem., 1995, 43, 2542.

8. E. Hernández-Sevillano, M. Villarroya, and J. L. AlonsoPrados, Weed Technol., 2001, 15, 447.

9. E. Ayano, Y. Okada, C. Sakamoto, H. Kanazawa, T. Okano, M. Ando, and T. Nishimura, J. Chromatogr., A, 2005, 1069, 281.

10. H. Kanazawa, T. Sunamoto, Y. Matsushima, A. Kikuchi, and T. Okano, Anal. Chem., 2000, 72, 5961.

11. C. Sakamoto, Y. Okada, H. Kanazawa, E. Ayano, T. Nishimura, M. Ando, A. Kikuchi, and T. Okano, J. Chromatogr., A, 2004, 1030, 247.

12. C. L. Arthur and J. Pawliszyn, Anal. Chem., 1990, 62, 2145.

13. Q. Z. Zhu, P. Degelmann, R. Niessner, and D. Knopp, Environ. Sci. Technol., 2002, 36, 5411.

14. V. N. Popov, Mater. Sci. Eng., 2004, 43, 61.

15. S. Sotiropoulou and N. A. Chaniotakis, Anal. Bioanal. Chem., 2003, 375, 103.

16. A. Salimi, C. E. Banks, and R. G. Compton, Analyst, 2004, 129, 225.

17. A. Javey, J. Guo, Q. Wang, M. Lundstrom, and H. Dai, Nature, 2003, 424, 654.

18. R. Q. Long and R. T. Yang, J. Am. Chem. Soc., 2001, 123, 2058.

19. Y. Q. Cai, G. B. Jiang, J. F. Liu, and Q. X. Zhou, Anal. Chim. Acta, 2003, 494, 149.

20. Y. Q. Cai, G. B. Jiang, J. F. Liu, and Q. X. Zhou, Anal. Chem., 2003, 75, 2517.

21. Y. Q. Cai, Y. Cai, S. F. Mou, and Y. Q. Lu, J. Chromatogr., A, 2005, 1081, 245.

22. P. Liang, Y. Liu, L. Guo, J. Zeng, and H. Lu, J. Anal. At. Spectrom., 2004, 19, 1489.

23. Q. X. Zhou, J. P. Xiao, W. D. Wang, G. G. Liu, Q. Z. Shi, and J. H. Wang, Talanta, 2006, 68, 1309.

24. Q. X. Zhou, W. D. Wang, J. P. Xiao, J. H. Wang, G. G. Liu, Q. Z. Shi, and G. L. Gao, Microchim. Acta, 2006, 152, 215. 